\title{
APRESENTAÇÃO
}

\section{v. 3, n. 2, mar./ago. 2017}

A publicação do sexto número desta revista de Filosofia da Informação enche de alegria a sua Equipe Editorial e o seu Comitê Editorial, e esperamos que contagie os nossos leitores e aos interessados na sua temática. Esta alegria decorre em primeiro lugar pelo fato de sobreviver em uma área em que muitos sucumbem: publicar por amor ao conhecimento.

Estamos felizes por delinear um contorno para a área da Filosofia da Informação com fortes cores da Filosofia prática. A política e a ética têm uma grande presença dentro do material publicado. Isto é especialmente pertinente em uma época em que a moral e a democracia estão ameaçadas como fundamentos e modos da integração social e da socialização. Nunca defender a dignidade humana, a liberdade e o bom viver foram tão necessários.

Estes temas são universais e esta é uma das razões que nos fazem insistir nos convites para pesquisadores de todos os países que colaborem com esta revista brasileira. Estamos abertos a publicação em português, espanhol e inglês. Queremos integrar o Grupo de pesquisa Filosofia e Política da Informação do IBICT - Instituto Brasileiro de Informação em Ciência e Tecnologia como cooperante com a rede internacional de pesquisadores, professores, estudantes e amantes da área.

É importante destacar o reconhecimento deste esforço pela CAPES - Coordenação de aperfeiçoamento do pessoal de ensino superior do Ministério da Educação. A revista foi incluída na lista Qualis de periódicos da área de Ciência da Informação, apesar de termos apenas três números publicados no último triênio avaliado. Este reconhecimento se soma a inclusão de artigos que publicamos nas bibliografias de Programas de Pós-graduação e de Cursos de graduação, bem como as citações em artigos e teses.

É um longo caminho a percorrer. Nesta hora devemos reconhecer, agradecer e elogiar o trabalho nesta área da pesquisadora Maria Nélida Gonzalez de Gomez, aposentada do IBICT e hoje professora do Programa de Pós-graduação em Ciência da Informação da UFF Universidade Federal Fluminense. Maria Nélida é uma pioneira e entusiasta da Filosofia da Informação com 30 anos de trabalhos de grande valor.

Este número da Logeion abre com um artigo do professor Ronald Day, chefe do Departamento de Ciência da Informação e Biblioteconomia da Universidade de Indiana em Bloomington. Este artigo sobre pop-política e fascismo é, de certo modo, uma sequência de artigo publicado em número anterior sobre a política nos Estados Unidos da América após a emergência de Donald Trump. A principal distinção é que este foi escrito após o sucesso eleitoral do populismo conservador

Neste artigo Ron Day discute o papel de parte da mídia social no retorno de políticas fascistas. Ele argumenta que, ao lado ou ao contrário de uma inteligência coletiva esclarecida 
que emergiria através da Internet, o que há é uma “inconsciência coletiva” ocupando a esfera política e buscando deslegitimar as instituições modernas de documentação verdadeiras e baseadas em evidências.

Em seu artigo no número anterior Ron Day analisou a relação entre o discurso político e as mídias sociais à luz da noção do discurso político como sendo (inata e positivamente) "curvo". Este conceito é usado por Bruno Latour, quando argumenta sobre a geometria da retórica política e suas pretensões à verdade. Day examina esta geometria a partir de estratégias retóricas pontuais e fragmentadas, empoderadas pela forma e uso das mídias sociais. O autor se debruçou sobre a campanha presidencial de Donald Trump nos EUA em 2015-2016, buscando contrastes e conexões em relação com as velhas mídias e tecnologias

A professora Raquel Recuero e o doutorando Felipe Bonow Soares, do Programa de Pósgraduação em Comunicação e informação da UFRGS - Universidade Federal do Rio Grande do Sul, apresentam artigo sobre a construção da opinião pública no Twitter, tomando como estudo de caso a nomeação de Alexandre de Moraes para substituir Teori Zavascki como ministro da Suprema Tribunal Federal.

A base teórica dos artigo é formada a partir das relações entre esfera pública e sítios de redes sociais. A análise adotou métodos mistos, baseados nas análises de contingência e de redes. $\mathrm{O}$ corpus deste estudo são 15.125 tweets usando “Alexandre de Moraes” como termo de coleta. Os dados foram analisados por meio das co-ocorrências entre os conceitos dos tweets, sendo possível observar os assuntos discutidos e posicionamentos dos participantes, em sua maioria contrários à indicação de Moraes.

O professor André Berten, emérito da Universidade de Louvain, discute despolitização, desmotivação e legitimidade nas sociedades atuais. O professor observa que as teorias políticas de inspiração kantiana propõem teorias da justiça, do direito e da democracia que pretendem ser justificadas racionalmente, seja a partir de uma teoria do contrato social, ou do consenso das pessoas razoáveis, ou de uma deliberação argumentada

Berten comenta que uma das pressuposições dessas teorias é que as pessoas podem ser motivadas pelo que aparece como mais justo, melhor, mais respeitoso das pessoas. Entretanto, o professor adverte que o "amor da justiça” ou mais simplesmente um "desejo de justiça” implicam sentimentos ou até paixões. Além disso sabemos como as paixões políticas podem ser avassaladoras, como nos casos extremos dos fascismos. Assim, devemos avaliar melhor o papel dos sentimentos e dos afetos na arena política.

Estes três artigos se articulam em torno da política nas sociedades atuais, destacando o papel das mídias sociais na formação da opinião e da vontade. $\mathrm{O}$ autor norte americano destaca o papel das mídias sociais no retorno de políticas fascistas, mostrando como o "inconsciente coletivo” age para deslegitimar as instituições da documentação verdadeira. O autor europeu argumenta que paixões políticas podem ser avassaladoras, como no fascismo, e considera necessário avaliar seu papel na esfera pública. 
O professor Roberto Lopes, da Universidade Federal do Pará, faz uma análise histórica sobre o desenvolvimento da biblioteconomia e Ciência da Informação do Leste Europeu entre o término da Segunda Guerra Mundial e os anos 1960. O estudo analisou a constituição e o desenvolvimento das bibliotecas na região, entre a idade média até o fim da Segunda Guerra Mundial. Em seguida discutiu os processos de reconstrução das bibliotecas e reorganização dos cursos em biblioteconomia desses países após o conflito, e da constituição de institutos em informação científica sob influência do Instituto Estatal de Informação Científico e Técnica (VINITI) soviético.

A pesquisa de Lopes identificou que os acervos documentais desses países do Leste Europeu seguiram um caminho de reestruturação que se manteria nas décadas seguintes. Contudo muitas vezes assimilaram, de forma impositiva, práticas e ideias produzidas por organismos e pesquisadores da União Soviética. Este padrão continuou, de forma irregular, até o fim da ocupação soviética na região com a queda do muro de Berlim em 1989.

A professora Jussara Borges e a mestre Gleise Brandão, do Instituto em Ciência da Informação da Universidade Federal da Bahia, apresentam artigo com a evolução contextoconceitual das competências Os autores acreditam que a interação propiciada pelas tecnologias de informação e comunicação pressionam o conceito no sentido da inclusão de aspectos como a relação de comunicação com o outro. Assim, defendem a promoção de modelo que acrescente à competência em informação o aspecto comunicativo, levando à proposta das competências infocomunicacionais.

Os dois autores enfatizam a necessidade de promover o desenvolvimento dessas competências a partir da conectividade e da meta-aprendizagem, aspectos defendidos pelo conectivismo e pela metaliteracy. A aproximação das competências infocomunicacionais a esses dois conceitos possibilitam avançar discussões a respeito da evolução do conceito de competência em informação para uma perspectiva metacognitiva, interativa e colaborativa.

O professor Jairo Dias Carvalho, da Universidade Federal de Uberlândia, apresenta um instigante artigo sobre as relações possíveis entre a Filosofia e a Convergência Tecnológica. O professor Carvalho investiga os paradigmas bióticos e cibernéticos presentes nas relações entre as biotecnologias e as tecnologias de informação e comunicação.

O artigo do professor Carvalho discute a relação da Filosofia com a Convergência Tecnológica NBIC, sinergia entre Nanotecnologias, Biotecnologias, Tecnologias da Informação e Ciências Cognitivas para a resolução de problemas. A partir de fórmulas de Andrew Feenberg busca situar a Filosofia da Tecnologia perante tal movimento. Finalmente, o autor indaga qual é a agenda necessária de pesquisa da Filosofia da Convergência Tecnológica?

O professor Francisco Antonio de Vasconcelos, da Universidade Estadual do Piauí, nos presenteia com um artigo original sobre a Filosofia Ubuntu, aqui considerada como uma das 
várias correntes da filosofia africana. A investigação busca se justificar considerando que a sociedade contemporânea é marcada por um individualismo e egocentrismo excessivos, além de uma valorização de bens materiais em detrimento do humano.

A filosofia Ubuntu, que se traduz em "Eu sou, porque nós somos", possui potencial ético capaz de fortalecer formas inovadoras de convívio social, no qual valores como respeito, confiança, solidariedade e generosidade são assumidos como fundamentais. O trabalho do professor Vasconcelos conclui que a filosofia Ubuntu representa uma das contribuições mais originais da filosofia africana, com potencial ético que não deve ser desprezado. O autor considera que Brasil e África precisam aprender a pensar de modo que nomina descolonizado.

A segunda parte deste número da revista Logeion compõe-se de quatro artigos que estão entrelaçados. Começa com a análise histórica da Biblioteconomia e das bibliotecas no Leste Europeu, com características distintas e subordinadas a burocracia stalinista da União Soviética. Ela prossegue com a discussão relação das competências informacionais com as tecnologias de informação e tecnologias. Os autores do artigo consideram que a inclusão tecnológica demanda observar os aspectos comunicacionais destas competências.

O artigo seguinte indaga qual é a agenda da Filosofia frente a Convergência de tecnologias de informação e comunicação, biotecnologia, nanotecnologia e ciências cognitivas. O último artigo apresenta a Filosofia Ubuntu como base de uma ética generosa e solidária, em oposição ao individualismo e a ganância. Não por acaso Ubuntu é o nome de um sistema operacional de código aberto para ser usado por qualquer pessoas sem dificuldades e construído a partir de um núcleo Linux.

A capa deste número da Logeion é a tela "Cor e corpo" de Narcisa Amboni, ex-diretora da Biblioteca Central da Universidade Federal de Santa Catarina. O corpo é pura cor, e a linha e a forma do modelo se confunde com a aquarela, segundo a pintora. A mulher é a própria tela, feita de paletas e de tintas. A tela foi escolhida para a capa do número lançado em março porque neste mês se comemora anualmente o Dia Internacional das mulheres.

Boa leitura! 